\title{
The Effect of Task Complexity and Strategic Planning Time on Writing Accuracy: A Case Study of Undergraduate Students at AMU
}

\author{
Malek Ahmad Kord \\ Department of English, Aligarh Muslim University, Aligarh, India
}

Email address:

Bahmankord9@gmail.com

To cite this article:

Malek Ahmad Kord. The Effect of Task Complexity and Strategic Planning Time on Writing Accuracy: A Case Study of Undergraduate Students at AMU. International Journal of Language and Linguistics. Vol. 6, No. 1, 2018, pp. 1-7. doi: 10.11648/j.ij11.20180601.11

Received: October 16, 2017; Accepted: October 23, 2017; Published: December 14, 2017

\begin{abstract}
Tasked -Based Language Teaching has widely provided learners some opportunities to learn spoken and written language through learning activities in the major of English Language Teaching (ELT). A growing body of research on the effects of task complexity on written productions, the present study explored the impacts of task complexity and strategic planning time on ESL learners' written performance in terms of accuracy. To this end, forty-five undergraduate English Language Learners, both male and female (within the age range of 17-25) have been recruited from Aligarh Muslim University. Two tasks were chosen as instruments for data collection. One is an argumentative essay and the other is a narrative task to measure the accuracy of the participants' written production, under different planning conditions (pre-task planning, withintask planning, and no planning). One-way MANOVA was employed as the statistical means of analysis. The findings revealed a significant effect of task complexity under different planning conditions on Error-free clauses (the percentage of clauses that do not contain any errors) and correct verb forms (the percentage of accurately used verbs in terms of tense, aspect, modality, and subject-verb agreement) regarding accuracy.
\end{abstract}

Keywords: Task-Based Language Teaching, Task Complexity, Strategic Planning Time, Accuracy

\section{Introduction}

Since the 1990s, in language education and learning tasks have been the concentration of attention as a unit of analysis [1-7]. Task-based language teaching (TBLT) uses the task as the essential unit of its analysis and emphasize the creation of meaning without any preceding instruction of language forms So, learners can use any strategies or forms to do the task and achieve the task goal [8]. Research into TBLT is essentially conducted due to deal with the problem of determining the related classifying and sequencing principles for designing and organizing tasks for task-based syllabi [9-11] and has mostly concentrated on discovering the effects of task design and task characteristics on task performance [12], [13-16], believed that TBLT is a response to a better understanding of language learning process. [17], divided planning time in the field of task-based language teaching into pre-task planning (rehearsal and strategic planning), planning happens before the performance of the task and within task planning (pressured and unpressured) regarding when planning takes place.

Several studies have been accomplished on the effect of different task characteristics on L2 learners' performance but, few studies have been carried out to investigate the effects of task complexity and strategic planning time. To fill this gap, this study investigates the effects of task complexity and strategic task planning on ESL learners' written performance in terms of accuracy, based on two different cognitively demanding tasks, namely, argumentative essay and narrative task writing under different planning conditions. The rationale for using two different types of writing with different complexity levels lies in available theories of language production: [18-20] and [15], [21] consider task complexity as the amount of attention a task demands from the learners. The underlying assumption of their Limited Attentional Capacity Model is that attentional resources are 
limited and increasing the complexity of tasks reduce attention capacity. As their attentional limits are reached, learners will prioritize processing for meaning over processing for form. Moreover, attending to one aspect of performance (complexity, accuracy, or fluency of language) may well mean that other dimensions suffer due to the learner's processing capacity.

\subsection{Task-Based Language Teaching}

Since 1980s, the introduction of task-based language pedagogy, tasks play a major role in second language acquisition (SLA) research and language teaching. In a task based syllabus, pedagogic tasks would be arranged to increasingly approximate the demands of real-world target tasks [7]. The essential research into task-based learning in SLA is evident in the vast amount of publications connected to task-based language learning, teaching, and testing [22], [23], [24], [25], [26], [9], [27], [28], [29], [10], [7], [18], [19], [20], [30].

One of the most important approaches for teaching second or foreign language is TBLT that appears to involve learners in interactional authentic language use by getting learners to complete a series of tasks. This approach aims to enable learners to obtain a new language system in addition to procedural their existing knowledge. In other words, it tries to make L2 learners use their linguistic resources to learn a new language [31].

\subsection{Task Complexity}

Complexity is characterized as "the extent to which the language produced in performing a task is elaborated and varied [25], p.340)" and pertains to learners' tendency to take risks to use the cutting edge of their linguistic knowledge which may ultimately lead to the process of restructuring [32], [33].

Robinson defined Task complexity as "the result of the attentional, memory, reasoning, and other information processing demands imposed by the structure of the task to the language learner. These differences in information processing demands, resulting from design characteristics, are relatively fixed and invariant" [34], p: 29).

Robinson's Cognition Hypothesis [34], [10], [7], [35] claims that increasing the cognitive demands of tasks along certain scopes will; (a) push learners to greater accuracy and complexity of L2 production in order to meet the greater functional and conceptual communicative demands they place on the learner; (b) promote interaction, and heightened attention to and memory for input, so increasing learning from the input; as well as (c) performing simple to complex task in sequences by participants will also lead to automaticity and efficient planning of the components of complex L2 task performance (d) longer term retention of input. More significantly, the Cognition Hypothesis predicts that along resource-directing scopes more interactive complex tasks will result in greater amounts of interaction, and negotiation for meaning.

Table 1. Robinson's framework distinguishes three task components: task complexity, task conditions and task difficulty factors [7], p. 5).

\begin{tabular}{lll}
\hline Task Complexity (cognitive factors) & Task Conditions (interactional factors) & Task Difficulty (learners factors) \\
\hline $\begin{array}{lll}\text { (a) resource-directing } & \text { (a) participation variables } & \text { (a) affective variables } \\
\text { e. g., } \pm \text { few elements, } \pm \text { Here-and-Now, } \pm \text { no } & \text { e. g., closed/ open, one-way/two-way, } & \text { e. g., motivation, anxiety, confidence } \\
\text { reasoning demands } & \text { convergent/divergent } & \text { (b) ability variables } \\
\text { (b) resource-dispersing } & \text { (b)participant variables } & \text { e. g., working memory, intelligence, aptitude } \\
\text { e. g., } \pm \text { planning, } \pm \text { single task, } \pm \text { prior knowledge } & \text { e. g., same/different gender, familiar/unfamiliar, } & \text { power/solidarity }\end{array}$ \\
\hline
\end{tabular}

The two most significant models of task complexity are the Robinson's Triadic Componential Framework [34], [10], [7], [35] and the Limited Attentional Capacity Model developed by Skehan \& Foster [18], [19], [20], [15], [21].

\subsection{Types of Task Planning}

Task planning is divided into two main types. This distinction is in terms of when planning takes place. Pre-task planning (PTP) refers to planning that happens before the learner performing the task. It includes what [36] calls 'preparatory attention' that helps in performing actions with greater accuracy and speed. The other type of planning time is within-task planning (WTP) which refers to planning that takes place while performing the task [17].

\subsubsection{Pre-Task Planning}

Rehearsal and strategic planning are two types of pre-task planning. Although both rehearsal and strategic planning require that learners be engaged in some activities to prepare for the task, there is a distinct difference between them. In rehearsal, learners are given the opportunity to do the task before the 'main performance [17]. At the first time, the performance of the task is considered as a preparation for the task for the main and final performance. On the other hand, strategic planning time, which is the focus of this study, entails learners' preparation of the content of the task that learners will perform it. In this type of planning, L2 learners have access to the actual task materials [17].

\subsubsection{Within-Task Planning}

Within-task planning differs from pre-task planning in terms of while the planning takes place. Two types of within planning are pressured and unpressured planning. In pressured, learners usually not need to have enough time to plan online, how to perform the task, while in unpressured within-task planning they are given enough time to plan the task they will perform on [17].

\subsubsection{No Planning}

In no planning, learners were required to carry out the task without any instruction that is given by the researcher. They were extremely pressured to express their ideas and plan their 
written production. They should carry out the task within the designated time limit as well.

\subsection{Accuracy}

Accuracy is usually considered as the simplest construct of writing components and refers to the degree of conformity to certain language usage norms, mainly in the areas of lexicon and grammar. [37] define accuracy as 'the conformity of second language knowledge to target language norms' (p. 4). [38] defined accuracy as 'the extent to which an L2 performance deviates from a norm' (p.4) In the SLA literature, accuracy is related to the controlled processing as well as capitalizing on the rule-based system, which is essentially a repertoire of rules used for formulating new sentences, [39].

\section{Research Hypothesis}

There isn't any significant difference between task complexity and strategic planning time on ESL learners' writing accuracy.

\section{Research Question}

To what extent task complexity and strategic planning time effect on ESL learners' writing accuracy?

\section{Research Methodology}

The methodology for the research study is quantitative. It has been divided into three sections pre-test of TOEFL (In order to evaluate the validity of the study and to ensure the homogeneity of participants), narrative task writing and argumentative essay writing, under different planning conditions (pre-task planning, within-task planning, and no planning).

\subsection{Participants}

One hundred undergraduate ESL learners of the final year of BA in the field of English both male and female (within the age range of 17-25) have been recruited from Aligarh Muslim University. In order to evaluate the validity of the study and to ensure the homogeneity of participants, a reliable pre-test of TOEFL was given to them. Thus, before the main writing task, participants were given the writing section of an institutional TOEFL to homogenize them regarding their writing proficiency and to cross out the outliers. Thus 45 learners at the same proficiency level in writing continued with the next task. The participants of this study were selected randomly on the basis of their performance on the pre-test. Then, they were randomly assigned into three groups namely pre-planning, within planning and no planning groups.

\subsection{Instruments}

In this study, two tasks were chosen as instruments for data collection. One is argumentative essay and the other is a narrative task to measure the accuracy of the participants' written production.

\subsection{Accuracy Measures}

For accuracy measurement the following two criteria will be used:

a) Error-free clauses: the percentage of clauses that do not contain any errors. Errors were defined as deviant from standard norms concerning syntax, morphology, and lexicon. Lexical errors are defined as errors in lexical form or collocation (e. g., *I was waiting you). So, all errors in syntax, morphology, and lexical choice will be considered.

b) Correct verb forms: the percentage of accurately used verbs in terms of tense, aspect, modality, and subject-verb agreement.

\subsection{Data Collection}

For data collection, two different tasks have been employed: the first task was a narrative task (summer routine story), the task required participants to write a story based on a set of six pictures. The second task was an argumentative writing task in which the three groups were supposed to compose an argumentative essay under different planning conditions. The topic was: "Some people argue that the Instagram has caused a lot of harm to young people. Others argue that the Instagram has brought many benefits to young people. What is your opinion? Use specific reasons and examples to support your answer."

All the participants of three groups were given 30 minutes to perform the tasks. In this phase, the pre-task planner group was asked to perform the task with 10 minutes for strategic planning. The participants of within task, planner group, were asked to perform the same task, but they were not given any time for planning. They had thirty minutes to compose their ideas. However, the no planning group did not have any opportunity to receive instruction.

\subsection{Data Analysis}

All writing productions of different groups under the conditions mentioned above will be segmented, coded, and scored based on the measures chosen for assessing accuracy. The data will be segmented, coded, and scored by two independent experts. Then, inter-coder/inter-rater reliability coefficient magnitudes were estimated. SPSS version 22.0 was used to check the normality of distribution via skewness and kurtosis indices. Accuracy will be submitted to MANOVA, followed by Post-Hoc Scheffe tests.

\section{Results of Research Question}

This research question was concerned about the effect of task complexity and strategic planning time on accuracy. The study sought to investigate the following research question: What is the Effect of manipulating task complexity and planning the time of writing accuracy of Indian ESL learners?

To provide a plausible answer to this research question 
two measures were used: (a) Error Free Clause, calculated by the number of error per clause and (b) Correct Verb Form, estimated by the number of correct verb forms used in their writings. Table 2 illustrates descriptive statistics on writing accuracy.

Table 2. Descriptive statistics of Argumentative and narrative task writing on Accuracy.

\begin{tabular}{llll}
\hline \multirow{2}{*}{ Task planning condition } & Argumentative Essay & & Narrative task writing \\
\cline { 2 - 4 } & Mean & Std Deviation & Mean \\
\hline Pre-task planning & .60 & .14 & .53 \\
Error free clause & .55 & .17 & .50 \\
Correct Verb Forms & & & .12 \\
Within task planning & .74 & .15 & .68 \\
Error free clause & .75 & .18 & .63 \\
Correct. Verb. Forms & & & .15 \\
No planning & 1.65 & 1.56 & 1.20 \\
Error free clause & 1,60 & 1.20 & 1.12 \\
Correct. Verb. Forms & & 1.22 \\
\hline
\end{tabular}

Descriptive statistics indicate that the PTP group in narrative task writing produced more error free clauses $(\mathrm{M}=.53 ; \mathrm{SD}=.12)$ than the WTP $(\mathrm{M}=.68 ; \mathrm{SD}=.11)$ and $\mathrm{NP}$ groups $(1.20 ; \mathrm{SD}=1.22)$. Furthermore, the descriptive statistics showed that the participants in the PTP group produced more correct verb forms in narrative task writing $(M=.50 ; \mathrm{SD}=.15)$ compared to WTP group $(\mathrm{M}=.63 ; \mathrm{SD}=.13)$ and $\mathrm{NP}$ group $(\mathrm{M}=1.12 ; \mathrm{SD}=1.14)$ in their writings.

Argumentative Essay writing also provided similar results to that of narrative task writing; in the case of error free clause, PTP group $(\mathrm{M}=.60 ; \mathrm{SD}=.14)$ outperformed WTP
$(\mathrm{M}=.74 ; \mathrm{SD}=.15)$ and $\mathrm{NP}$ groups $(\mathrm{M}=1.65 ; \mathrm{SD}=1.56)$. So, it can be concluded that regarding error free clause production, pre-task planners had a better performance than those of within task planners and no task planners. Regarding correct verb form production, similar results emerged; again PTP produced more correct verb form $(\mathrm{M}=.55 ; \mathrm{SD}=.17)$ compared to $\mathrm{WTP}(\mathrm{M}=.75 ; \mathrm{SD}=.18)$ and $\mathrm{NP}(\mathrm{M}=1.60 ; \mathrm{SD}=1.20)$.

Descriptive statistics show that in the case of task complexity, learners in narrative task produced more accurate language regarding error free clauses and correct verb forms compared to argumentative in terms of accuracy.

Table 3. Summary of MANOVA test results on writing Accuracy.

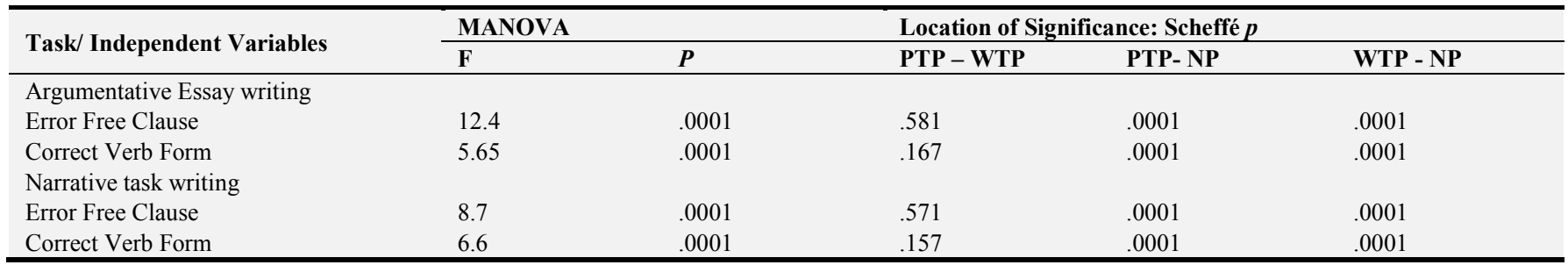

Using Multivariate analysis of variance, significant effects of task planning conditions and task complexity were detected. The results of MANOVA for both narrative and argumentative tasks, as displayed in a table 2 , indicate a significant effect of planning conditions on students' writing Accuracy. With regard to error free clauses, a significant effect of planning conditions was established. It displays that there is a significant difference among the groups. It is also necessary to find out where the difference is posited. Thus, Scheffe Post-hoc tests were conducted to compare the groups, and to show where the difference is [significant value less than 0.05 is a significant and value greater than 0.05 is not significant]. As shown in the Table 3, post hoc Scheffe test results indicate that there is no significant difference between PTP and WTP groups $(p=.581)$ regarding Error Free clauses in argumentative task writing. However, considering narrative task writing, there were marginally significant differences between the groups $(p=.571)$. In the case of Correct Verb Form, the difference between PTP and WTP groups were.167 and.157, respectively. However, considering argumentative and narrative task writing, there were significant differences among the other groups $(p=.0001)$. The difference between PTP and NP group was also significant $(p=.0001)$. Regarding Error-free clauses and correct verb form, the difference between PTP, NP and WTP, NP were significant $(p=.0001)$ However, it can be concluded that based on argumentative and narrative task writing under different planning conditions, there were highly significant differences between PTP and NP.

\section{Discussion}

Concerning the effect of task complexity and strategic planning time on writing accuracy, the outcomes of this study indicated that regarding error-free clauses, in both narrative and argumentative essay writing tasks, the PTP group outperformed compared to WTP and NP groups. However, in the case of using correct verb form similar results emerged; again PTP produced more correct verb forms compared to WTP and NP.

With respect to the effects of strategic planning time on ESL learners' written production regarding accuracy in the 
narrative task, it was shown that strategic planning time in the simple task (narrative) led to more accuracy. It means, the participants who performed the simple task with strategic planning time, pre-task and within task planners produced more accurate language than the participants who have done it without strategic planning time (NP). The outcomes of the present study are in line with the findings of studies like [12], [40], [25], [29]. Though, the outcomes of the present study in terms of accuracy ran against the results of the studies like [41], [2], [42], [43].

Regarding the effects of strategic planning time on ESL learners' writing regarding accuracy in the argumentative task, the results of the present study indicated that there was a significant difference between strategic planning and learners written production in terms of accuracy, in the complex task (argumentative). The participants who performed a simple task (narrative), produced more accurate language compared to the participants who performed a complex task (argumentative) in the case of accuracy under different planning conditions, regarding Error free clauses and correct verb forms. The results of this study are in line with the results of studies like [12], [25], [29], [36]. Nevertheless, the findings of the present study regarding accuracy ran against the results of the studies like [40], [2], [42], [41]. The higher rate of accuracy in a complex task can be interpreted regarding Long's view [44] that a complex task will lead learners to develop their interlanguage resources. The accuracy can also be attributed to a load of attention paid by the learners to the difficult task (argumentative) than paid to the easy task (narrative). According to Given's [45] model accuracy can also be interpreted regarding pragmatic and syntactic that demanding learners to use greater syntactic resources and abilities which will lead to an increase in grammatical accuracy.

Considering the outcomes of the data analysis on task complexity and accuracy of ESL learners' written production, there was a significant difference between task complexity (narrative and argumentative essay) and ESL learners' written performance in terms of accuracy. The results of this study regarding the effect of task complexity on accuracy are in line with the predictions of Cognition Hypothesis [35]. This production of less accurate language in terms of task complexity can be attributed to the fact that [46], [36] learners can't pay attention to language forms without a loss of attention to content and when they are free to allocate attention, they prioritize concern for the content over concern for the form.

\section{Conclusions}

On the basis of above results, the following conclusions can be listed:

1. Task planning in terms of, accuracy (Error free clauses, correct verb forms) in the argumentative essay and narrative task affected learners writing accuracy, pre-task planners outperformed compared to within and no planners.

2. Task complexity in terms of, accuracy (Error Free clauses, correct verb forms) in the argumentative essay and narrative task affected learners writing accuracy, pre-task planners produced more Error free clauses and correct verb forms compared to within and no planners.

3. Post hoc analyses revealed that there was a statistically significant difference in writing accuracy based on task planning conditions, It shows that there was a significant difference among the groups also, the results indicated that there was a marginally significant difference between PTP and WTP groups.

\section{Implications}

The results of this study from the view of language pedagogy, assume particular importance in that they provide empirical support for the use of tasks in language classrooms. One of the most important criticisms leveled at task-based language teaching and learning is that attention to form is thought to be limited to the feedback which is given to language learners by their teachers or peers [31]. Also, TBLT has criticized because performing a task by its meaningcentered and outcome-oriented nature may at best lead to the production of impoverished and pidginized language which is of very little value for L2 acquisition [47].

This study exposed that task complexity and strategic planning time affected significantly on the quantity and quality of ESL learners' written production. As well as, it proposes that PTP and WTP have somewhat different effects. It has significant implications for both writing pedagogy and testing. That is, teachers may be able to manipulate the aspect of writing complexity that L2 writers attend to by changing the task conditions to permit sometimes for PTP, sometimes for WTP and sometimes for both. Eventually, teachers who wish to enable L2 writers to present their best products for assessment may need to ensure that opportunities for both types of planning are available to them.

Another educational implication of the present study is the confirmation that PTP activities may effectively promote the quality of written language production in ESL classes. Considering the findings of this study as well as those of previous planning research, it appears to be a feasible option for teachers to provide learners with explicit instruction on how to make a plan rather than simply allow them extra time for planning. Thus, learners can get the most of their planning time to prepare for writing. While adopting a strategic device such as concept mapping, teachers may need to set up a teaching period of a certain length to familiarize their students with the specific strategy.

\section{References}

[1] Long, M. (Ed.) (2007). Problems in SLA, Mahwah, NJ: Erlbaum.

[2] Gilabert, R. (2005). Task complexity and L2 narrative oral production. Unpublished Ph.D. dissertation. University of Barcelona, Spain. 
[3] Gilabert, R. (2007). Effects of manipulating task complexity on self-repairs during L2 oral production. International Review of Applied Linguistics, 45, 215-240.

[4] Ortega, L. (2005). What do learners plan? Learner-driven attention to form during pretask planning. In Ellis, R. (Ed.) Planning and task performance in a second language. Amsterdam: John Benjamins.

[5] Rahimpour, M. (2007). Task complexity and variation in L2 learners' oral discourse. Working Papers in Language and Linguistics, University of Queensland, 1-9.

[6] Rahimpour, M. (2008). Implementation of task-based approaches to language teaching. Pazhuhesh-e-Zabanha-ye Khareji Journal, University of Tehran, 41, 45-61.

[7] Robinson, P. (2005). Cognitive complexity and task sequencing: studies in a componential framework for second language task design. International Review of Applied Linguistics, 43, 1-32.

[8] Willis, D., \& Willis, J. (2001). Task-based language learning. In R. Carter and D. Nunan (Eds.), The Cambridge guide to teaching English to speakers of other languages (pp. 173-179). Cambridge: Cambridge University Press.

[9] Long, M., \& Crookes, G. (1992). Three approaches to taskbased syllabus design. TESOL Quarterly, 26 (1), 27-56.

[10] Robinson, P. (2003). The cognition hypothesis, task design, and adult task-based language learning. Second Language Studies, 21 (2), 45-105.

[11] Robinson, P. (2006). Criteria for classifying and sequencing pedagogic tasks. In M. P. G. Mayo (Ed.), Investigating tasks in formal language learning, (pp. 7-26). Clevdon: Multilingual Matters.

[12] Tavakoli, p., \& Skehan, P. (2005). Strategic planning, task structure, and performance testing. In R. Ellis (Ed.), Planning and task performance in a second language (pp. 239-277). Amsterdam: Benjamins.

[13] Tavakoli, P., \& Foster, P. (2008). Task design and second language performance: the effect of narrative type on learner output. Language Learning, 58 (2), 439-473.

[14] Skehan, P. \& P. Foster (1997). Task type and task processing conditions as influences on foreign language performance. Language Teaching Research 1: 185-211.

[15] Skehan, P. \& Foster, P. (1999). The influence of task structure and processing conditions on narrative retellings. Language Learning, 49 (1), 93-120.

[16] Rahimpour, M. (2010). Current trends on syllabus design in FL instruction. Procedia Social and Behavioral Sciences, 2, 1660-64.

[17] Ellis, R (Ed.) (2005). Planning and task performance in a second language. Amsterdam: John Benjamins.

[18] Skehan, P. (1998). A cognitive approach to language learning. Oxford: Oxford University Press.

[19] Skehan, P. (2001). Tasks and language performance assessment. In M. Bygate, P. Skehan, \& M. Swain (Eds.), Researching pedagogic tasks: Second language learning, teaching and testing (pp. 167-185). Harlow: Pearson Education Longman.
[20] Skehan P. (2003). Task based instruction. Language Teaching 36 (1): 1-14.

[21] Skehan, P. \& Foster, P. (2001). Cognition and tasks. In P. Robinson (Ed.): Cognition and Second Language Instruction. (pp. 149-187). New York NY: Cambridge University Press.

[22] Bygate, M. (2001). Effects of task repetition on the structure and control of language. In M. Bygate, P. Skehan, \& M. Swain (Ed.), Researching pedagogic tasks: Second language learning, teaching and testing (pp. 23-48). London: Longman.

[23] Ellis, R. (1987). Inter language variability in narrative discourse: Style shifting in the use of the past tense. Studies in Second Language Acquisition, 9 (1), 1-20.

[24] Ellis, R. (2003). Task-based language learning and teaching. Oxford, U. K.: Oxford University Press.

[25] Foster, P., \& Skehan, P. (1996). The influence of planning and task type on second language performance. Studies in Second Language Acquisition, 9, 12-20.

[26] Larsen-Freeman, D. (2006). The emergence of c, Fluency, and accuracy complexity in the oral and written production of five Chinese learners of English. Applied linguistics, 27, 590-619.

[27] Ong, J. \& Zhang, L. J. (2010). Effects of task complexity on the fluency and lexical complexity in EFL students' argumentative writing. Journal of Second language Writing, 19, 218-233.

[28] Ong, J. \& Zhang, L. J. (2013). Effects of the manipulation of cognitive processes on EFL writers' text quality. TESOL quarterly, 47 (2), 375-397.

[29] Ortega, L. (1999). Planning and focus on form in L2 oral performance. Studies in Second Language Acquisition, 21, 109-148.

[30] Yuan, F. \& R. Ellis. (2003). The effects of pre task and on-line planning on fluency, complexity and accuracy in L2 monologic oral production. Applied Linguistics 24 (1): 1-27.

[31] Ellis, R. (2009). Task-based language teaching: Sorting out the misunderstandings. International Journal of Applied Linguistics 19 (3), 229-246.

[32] Ellis, R. (2008). The study of second language acquisition. Second edition. Oxford: Oxford University Press.

[33] Ellis, R., \& Barkhuizen, G. (2005). Analyzing Learner Language. Oxford: Oxford University Press.

[34] Robinson, P. (2001). Task complexity, task difficulty, and task production: exploring interactions in a componential framework. Applied Linguistics, 22 (1), 27-57.

[35] Robinson, P. (2007). Task complexity, theory of mind, and intentional reasoning: effects on L2 speech production, interaction, uptake and perceptions of task difficulty. International Review of Applied Linguistics, 45 (3), 193-213.

[36] Schmidt, R. (2001). Attention. In P. Robinson (Ed.): Cognition and second language instruction. Cambridge: Cambridge University Press.

[37] Wolfe-Quintero, K., Inagaki, S., \& Kim, H. Y. (1998). Second language development in writing: Measures of fluency, accuracy, and complexity. University of Hawai'i, Second Language Teaching and Curriculum Center. 
[38] Housen, A., \& Kuiken, F. (2009). Complexity, accuracy, and fluency in second language acquistion. Applied Linguistics 30 (4), 461-473.

[39] Schmidt, R. (1992). Psychological mechanisms underlying second language fluency. Studies in Second Language Acquisition 14: 357-385.

[40] Ishikawa, T. (2006). The effects of task complexity and language proficiency on task- based language performance. The Journal of Asia TEFL, 3 (4), 193-225.

[41] Hosseini, P. \& Rahimpour, M. (2010). The Impact of Task Complexity on L2 Learners' Written Narratives, CCSE, 3 (3), 198-205.

[42] Salimi, A. \& Dadashpour, S. (2012b). Task Complexity and Language Production Dilemmas (Robinson's Cognition Hypothesis vs. Skehan's Trade-off Model). Procedia-Social and Behavioral Sciences, 46, 643-652.
[43] Mehrang, F. \& Rahimpour, M. (2010). The impact of task structure and planning conditions on oral performance of EFL learners. Social and Behavioral Sciences, 2, 3678-3686.

[44] Long, M. (1985). A role for instruction in second language acquisition: task-based language teaching. In K. Hyltenstam \& M. Pienemann (Eds.), Modelling and assessing second language acquisition (pp. 77-99). Clevedon: Multilingual Matters.

[45] Givon, T. (1989). Mind, code, and context. essays in pragmatics. Hillsdale, NJ: Erlbaum.

[46] Van Patten, B. (1990). Attending to content and form in the input: An experiment in consciousness. Studies in Second Language Acquisition, 12, 287-301.

[47] Seedhouse, P. (1999). 'Task-based interaction'. ELT Journal 53: $149-156$ 